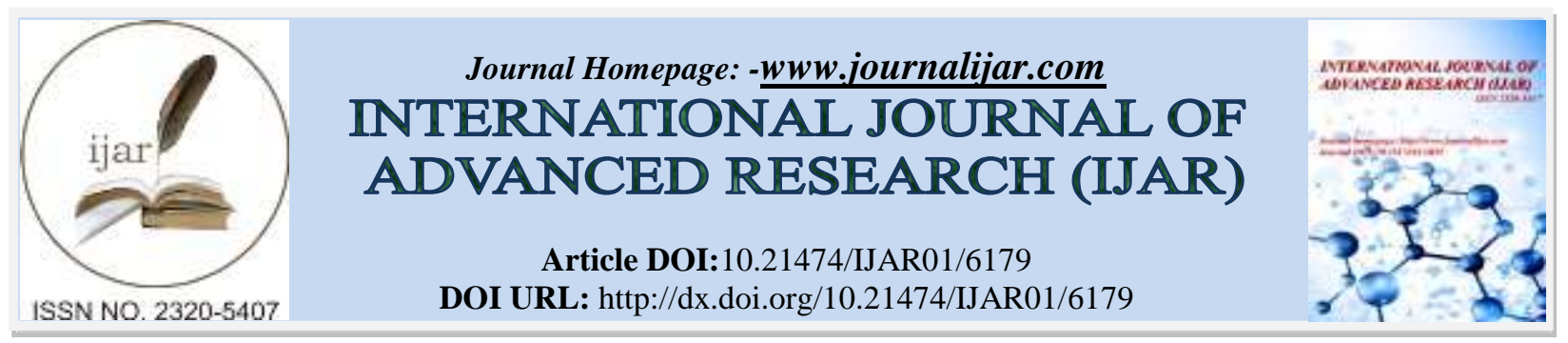

RESEARCH ARTICLE

\title{
ASPECTUAL TYPE OF OBSERVING TIME, VERBS OF MOTION; COGNITIVE APPROACH.
}

Mirsanov Gaybullo Kulmuradovich.

$\mathrm{Ph} . \mathrm{D}$, teacher of Samarkand State Institute of Foreign Languages Uzbekistan, Samarkand city.

\section{Manuscript Info}

Manuscript History

Received: 01 November 2017

Final Accepted: 03 December 2017

Published: January 2018

Keywords:-

Aspect, Aspectual Situation, Aspectual

Semantics, Scope, Event, Motion Verbs,

Beginning, Intensity, Duration,

Completeness, Iteration, Result,

Singularity.

\begin{abstract}
The manuscript presents an investigation on aspectual semantics in English and Uzbek typologically. The main focus is directed to cognitive investigation of aspectual semantics. Aspectual semantics associates telic and atelic predicates on the scope of an observerin cognitive research. A cognitive approach in investigation of aspectual phenomena is linked with type of aspectual situation. It serves to determine aspectual situation types.
\end{abstract}

Copy Right, IJAR, 2018,. All rights reserved.

\section{Materials and methods:-}

Aspectual investigations are mostly based on the grammatical category vid (aspect), where two opposed phenomena sovershenniy vid (perfective aspect) and nesovershenniy vid (imperfective aspect) are revealed. There have been attempts to find aspectual meanings in other languages on the basis of Slavic aspect. Then, the investigation involved findings not only grammatical categories, but other categories influencing verb semantics. That occurs in "Functional semantic field" combining all contextual units influencing predicate semantics. Aspectual semantics is also considered to have cognitive conceptual basis, related sensor-motor relation of perception ${ }^{2}$.Aspectual semantics has been main research direction of linguists such B. Comrie, O. Dahl, Z. Vendler,W. Croft, R. Langacker, M. Krifika,H. Verkuyl, Yu.Maslov, V. Bondarko, E. Paducheva and others.

Methods of the research: descriptive method, method of comparative typology, method of functional semantic analysis, method of associative experiment, distributive analysis,statisticanalysis,cognitiveconceptualanalysis,structural- semantic approach.

\section{Results and Discussion:-}

${ }^{1}$ Bondako A.B. The principles of functional grammar and the issues on aspectology. - L.: 1983. $-208 \mathrm{c}$

${ }^{2}$ Langacker, Ronald W. Foundations of Cognitive Grammar, Volume 1: Theoretical Prerequisites.Stanford, CA: Stanford University Press. 1987. -248p.,Langacker Ronald W.. Cognitive Grammar. Oxford University Press. 2008. -571p.,Paducheva E.V. Telicity and incremental theme.Russian Linguistics.33: 2009. -P 109-119., Seuren Pieter. Language in Cognition Published in the United States by Oxford University Press Inc., New York. 2009. 387p.,Geeraerts Dirk.Theories of Lexical Semantics. Oxford University Press. 2010. 342p., Evans Vyvyan. Language and Time.A Cognitive Linguistics Approach.Cambridge University Press. United Kingdom. 2013. 282p. 
A wide and varied array of notions are capable of being coded in the verb. Chief among these are the closely associated notions of tense, modality, and aspect ${ }^{3}$. Aspect is closely associated with both grammatical and semantics of the verb. Verb semantic meanings are not fixed, they are acquired through interaction with pragmatic, social, cultural, environmental context. So the verb is the most flexible unit of a language. O. Dahl being on the position of semantic approach to aspect supposes that morphological forms are not enough to identify perfective and imperfective. He tends to semantic approach by saying "perfective and imperfective verbforms tend to be distinguished from each other by rather more complex devices thanmany other items in morphology" according to language system ${ }^{4}$. Semantic meaning of verbs can be compared to lizards changing its colour according to environment and conceptualize in the mind as process, state, beginning of an action, end of an action or a whole event. Conceptualization is closely linked with the situation. That's why, I'm going to use term aspectual situation for aspectual meanings (process, durativity, terminativity, inchoativity, iterativityetc) expressed by a predicate. My earliar findings ${ }^{5}$ indicate that aktionsart features of verb lexemes (bounded / unbounded) influence greatly to form an aspectual situation. Within one verb, there may be expressed several aspectual situations with the influence of context and at the same time with the bounded or unbounded features of a verb lexeme. For example, the verb to know is included to unbounded verb lexemes (Langacker calls them imperfective) and in any case it denotes a durative meaning. To conceive some kind of terminative meaning there is used another expression to get to know in English. But, in Uzbek the equivalent of the verb to know "bilmoq" may be conducted with both unbounded and bounded features. Bounded feature is realized with the help of grammatical form, that is auxiliary verb which influence for the bounded meaning. For example: men buma'lumotnibilaman (I this information know)- I know this information. Men buma'lumotnibiliboldim (I this in formation know receive) - I have got to know this information. Motion represents a dynamic force by nature and plays great role in human life. Linguistic sense of motion is considered differently across languages. Each language has its own properties to represent the motion, that's how the owners of the language conceptualize the motion. The meaning of motion verbs are closely linked with space, trajectory (direction), path, time and so on. That's why, Pourcel suggests term "motion event" for predicate usage of motion verbs. Pourcel also takes into account aspectual semantics of motion according to nominal units. The author brings out that, the concept of 'motion event' is extended to involve not only (1) 'telic paths', such as those on (2), but 'atelic' or 'locative' paths, 'e.g. DOWN, ALONG, AROUND'.

Motion is an ideal domain of investigationfor several reasons: (i) it pervades human experience and is thus an essential domain of conceptualisation and expression, (ii) it is a complex enough domain not to be amenableto neurophysiological determinism, (iii)it remains experientially grounded in human and terrestrial physics and hence it may beculturally subjective to a limited extent only,(iv) it is expressed differently across languages, including closely-related ones ${ }^{7}$, and (v) its means of expression reach beyond lexical resources to the sentence andtext levels ${ }^{8}$. Some linguists suggest to the form of verbs according to their predicate usage verb-framed and satellite-framed languages. Satellite-framed constructions drive meaning of predicate with the influence of some other components of the predicate. Auxiliary verbs of Uzbek can serve to the main verb as a satellite and these satellite-frames (analytic forms) are concentrated to cognitive salience of motion. In English, satellites in, out suggest interior or outerior meaning the verb, and at the same time change of location. From the aspectual point of view it expresses terminative aspectual situation. While in Uzbek the kind of meaning may be conveyed in different ways, that's by locative frame and satellite frame:

U xonaga kirdi (he entered the room- he room into enter)

U xonaga kirib keldi

(He room enter come)

(He entered the room)

\footnotetext{
${ }^{3}$ Langacker R.W. Cognitive Grammar.A Basic Introduction.Oxford University Press, 2008. -P. 400.

${ }^{4}$ Dahl O. Tense and aspect in the languages / Empirical approaches to language typology. Berlin; New York : ed. Mouton de Gruyter, 2000. -P 16.

${ }^{5}$ MirsanovG.Aktionsart and aspect characteristics of neutron-limitative verbs of motion in Uzbek. Karaganda, Kazakhstan. 2009 г № 1 (53) - P. 17-21

${ }^{6}$ Pourcel S. S. Relativism in the linguistic representation and cognitive conceptualisation of motion events across verb-framed and satellite-framed languages.PhD Thesis, Department of Linguistics and English Language, University of Durham.2005.-P 154.

${ }^{7}$ Talmy, L. Lexicalisation patterns: Semantic structure in lexical forms. In Language Typology andSyntactic Description, T. Shopen (ed.), Cambridge: Cambridge University Press, Volume 3: 1985. -P 57-149.

${ }^{8}$ Evans V and Green M. Cognitive linguistics. AN INTRODUCTION. Edinburgh University Press, 2006. -P 372.
} 
In Uzbek aspectual meaning with motion verbs can be expressed more detailed than in English or Russian. The main determination on this basis is the auxiliary verbs, which show all the features of aspectual meaning.

It also should be noted that the kind (cognitive) approach for simultaneity of events at the view of an observer mainly discussed by E.Paducheva ${ }^{9}$. Scanning is associated with the observer's expressinga scope of event. Accordingly, an aspectual meaning of an event depends on how wide or short the scope is. The notion of "Scope" can be used to determine the coverage of observer's scanning the situation. Apparently, "scope" is also based on the quantity indicators of objects and the length of space. A small quantity of an object can be observed as short scope and can be considered as telic event: read a word. "Word" has a small quantity, so can be produced in one act. "Read a book" is considered to have wide scope. It can't be produced in one act, it takes a large amount of time, so atelic event. Thus wide scope and short scope are opposed to each other. But in Russian the kind of object takes special aspectual verb forms. For example: chitatknigu-prochitatslova. As an analytical form of verb, Uzbek predicates may describe different types of events or aspectual semantics with the help of an auxiliary verb: so'znio'qimoq (telic event) -short scope; kitobnio'qimoq (process, atelic event)- wide scope; kitobnio'qibbo'lmoq, kitobnio'qibchiqmoq, kitobnio'qibtugatmoq (process + terminate - telic event), describes completed process. Logically, reading a word (or a phrase) takes a short period of time, and can't be interrupted or remain unfinished. As for a book, a story or a sentence we spend wide range of time and it interrupted any time while reading and may not come to its end. As a result, reading a book (or a story) is conceived as a process. Aspectual meaning within a verb (if the verb is not perfective) depends on the scope of object it takes. Thus, "the object is conceptualized as a referent within semantic influence" 10

Defining aspectual meaning within 'scope' peculiar to the languages, where there is a weak indicator of grammatical form of aspect like English, Uzbek. Scanning can be the best model to describe events with motion verbs, where aspectual semantics can be clearly seen. Motion verbs are closely related to space, time and location. Aspectual semantics of motion verbs within 'scope' can be defined in the property of their directive features, characteristic features (related motion) of a subject and the conceiving time of a motion.

There have been distinguished three cognitive versions of concept by linguists: conceptual semantics, frame semantics, prototype semantics. Frame is considered to represent the structure of information in stereotyped situation. So, frame is interpreted as the structure of typical situation, which includes one or several episodes each having their own aspectual interpretation. On this basis, T.Beloshapkova distinguishes mono-situational and polysituational frames. The author states situation as forming surface semantic frame which may differ in denoting aspectual semantics. T.Beloshapkova distinguishes nine concepts of Russian aspectual meanings (singularity, duration, beginning, continuation, extent of manifestation, correlation with standard,) within the scope of three frames (surface, semantic, thematic) ${ }^{11}$.

Vendlerian classes have been considered the best way of aspectual classifying verb predicates. As for the states, activities, accomplishments and achievements everything is clear, but for accomplishments I may argue, because of their usage as both telic and atelic predicates.

Motion verbs have been classified into lexico-semantic group by many linguists. These classifications differ in some extant. To identify conceptual base and aspectual semantics denoted by motion verbs I'm going to represent my own

\section{Classification:-}

1. directive limited motion verbs (in English: to come, to arrive, to leave, to get etc.), (in Uzbek: kelmoq (come), ketmoq (leave), bormoq (go), etmoq (reach) etc.). These verbs fall into short 'scope' and the completeness can be easily observed by the observer: come to school, arrive home, get to the University, leave home; uygakelmoq, maktabgaketmoq, daryogaetmoq:

2. cover motion verbs (in English: to cross, to pass), (in Uzbek covering meaning can't be expressed within single verb lexeme. Covering a distance is expressed with analytical forms (main verb + auxiliary verb; bosibo'tmoq

\footnotetext{
${ }^{9}$ PaduchevaH.V. On the search of an observer: verbs to look and to be. Dialog. 2007. -P 436-443.

${ }^{10}$ Geeraerts D. Cognitive Linguistics: Basic Readings. Mouton de Gruyter. 2006. -P 78.

${ }^{11}$ BeloshapkovaT. V. Cognitive-discursive description the category of aspectality in modern Russian (dissertation) abstract.Moscow, 2008.-40p
} 
(cover pass), kesibo'tmoq (cross pass)). Cover motion verbs deal with covered distance and denote 'short scope', a passed distance on the view of an observer:

3. non-directive motion verbs (in English: to move, to walk, to swim, to fly (note: all these verbs may have direction or cover, but with the contextual influence or special adverbials), (in Uzbek: yurmoq, suzmoq, chopmoq). These verbs may denote both 'short scope' and 'wide scope' and the terminativity or nonterminativity can be defined with the help of contextual markers.

4. manner and rate motion verbs (in English: to shuffle, to tiptoe, to creep, tomarsh, totrot, towander, towade, tocrawl, torun, toride, todrive, to run, to chase etc), (in Uzbek: yugurmoq (walk), chopmoq, daydimoq, yo'rg'alamoq, sang'imoqvashukabilar). The scope can be determined in context and on observer's interpretation the situation. More detailed analysis of aspectual meaning is presented below.

The first group of verbs is related directive motion to a particular object or leaving located space, thus having either the end or beginning the action. The motion takes place within a particular distance, viewing as bounded. The scope of a motion can be clearly observed or realized.

Aspectual meanings depend on grammatical forms, contextual usage of verbs, bounded / unbounded features of verbs and also temporal and space indicators. Comprising all these, predicates denote different type of aspectual meanings. That's why, while analyzing a situation or an event, we have to conclude every detail influencing aspectual meaning. To differentiate aspectual semantics of a situation we have to conclude every usage of verbs, their inner bounded and undounded meanings within lexeme, contextual influence and also conceiving the situation or episode from the point of view of an observer.We are using the term "aspectual situation" for interrelated aktionsart (bounded / unbounded) features and aspect characteristics in speech[Rizaev, 1999: 39]. According to this, we use terms Inchoative Aspectual Situation (InchAS) to denote the beginning of an action, Inchoative+Process Aspectual Situation for both beginning and process, predicates with repetitive meaning Iterative Aspectual Situation (IAS), continual process Continuative Aspectual Situation (CAS), for the end of an action Terminative Aspectual Situation (TAS), duration can be expressed as durative aspectual situation (DAS) and so on.

Perfective verbs denote telic event and can be considered as Terminative Aspectual Situation (TAS) with short scope. The second predicate (event) 'crossed it' indicates coverage of a distance or dimensional scope and also can be formalized as TAS $=$ short scope.

I came to the courtyard, crossed it, .....(Hem, 194).

The richness of auxiliary verbs gives predicate different shades of meanings in Uzbek. This kind of even can be manifested different usage of auxiliary verbs having slight shade of meaning difference.

U hovliga keldi $=$ he came to the courtyard.

He courtyard came

U hovliga etib keldi. $=$ he came to the courtyard (with some effort).

He countryard reach come

U hovliga kelib etdi.

He countryard come reach $=$ he came to the courtyard ( similar to came up to the courtyard).

All these events in Uzbek are also predicted as TAS with short scope. The second event can be designated following way.

(u) hovlini kesib o'tdi = he crossed the courtyard

he courtyard cross pass

By the time I reached San Francisco in 1851, after crossing the Isthmus of Panama, the gold fields were crowded(London, 116);

An example given below is considered telic event without doubt. That's true in one point, change of position. But conceiving the event as a whole, the beginning of motion is presented with incremental process. That's beginning (inchoative) + process or Inchoative Processing Situation (Inch PS) is viewed as wide scope. Because of the end point of motion is not clearly given, and the motion hasn't reached to its destination.

We started off down the narrow road (Hem, 183);

Tor ko 'chabo'ylabyo'lgatushdig

Narrow road down (we) started off. 
The same meaning is observed in Uzbek.

One of the most controversial aspectual semantics is observed with the verb "to walk". Walking from school to the river is considered as achievement. We agree to this kind of comment, but it includes both durative motion in some distance and terminative situation reaching to the river. Let's consider examples given below.

The old lady walked slowly round the garden

Walking round the garden without interruption may continue hours, and if the process is taking place on the view of an observer, we may include it into wide scope of situation. Because, the end point of the situation is not seen and the motion is purely durative. Here, we can observe Process Aspectual Situation with wide scope. Another example indicates "to walk" having been boundered with final end point between location of a person and final point of motion the station. The coverage of distance and reaching destination point indicates T+PAS. Reaching destination point (the station) denotes terminative meaning. As for the motion cover from location up to station indicates that there is a process, so this process is considered as durative. From the point of view of an observer, it's a short scope. The location of action taking place is easily conceived.

How far the station, can I walk it?

Vokzalgacha uzoqmi? U yerga piyoda bora olamanmi? U erga yurib bora olamanmi?

There on foot can go (I)? There walk can go (I)?

Uzbek translation of the sentence can be given in several ways. The coverage of coming to the end point or covering as a whole is not so clearly conceived. Indication of the end point is usually described by -et, -kel auxiliary verbs. If we observe, both durative motion and completeness is peculiar to one situation.

Temporally adjacent progress through the event corresponds to spatially adjacent progress along the path. For example, in a canonical interpretation of John walked from the university to the capitol the event begins when Johnleaves the university, progresses temporally as John progresses adjacently along the path, making consistent, unidirectional progress, and ends when John reaches the capitol, which is when the entire path has been traversed ${ }^{12}$. When the verb 'to walk' has the meaning of manner, it may denote just non-directive motion. In this meaning the verb 'to walk' conducts as imperfective. From the point of aspectual semantics, it may be conceived as Processing Aspectual Situation (PAS) having wide scope. For example: He was short and old, with a white mustache and walked flat-footed(Hem,118).

The given example serves as a manner of motion without any direction or hint to completeness.

Processing Aspectual Situation is also conceived when the motion of location is described. For example: They all walked behind the carts (Stone, 392);

He walked in the rain, an old man with his hat off a carabineer on either side (Hem,201).

The scope between the beginning and the end is not seen. Walking somewhere else in a direction without indication to an end point may continue indefinite time. That's why, it is considered to no terminal end point. But, one may argue with me on the point that naturally any action or motion come to an end. In this case, I may say, that any state also has natural end. As many linguists consider state verbs, for example, 'to know' atelic or imperfective. Knowing something is acquired, that means it has the beginning. If something has the beginning, it also has the end. Let's not go too deeper and continue our analysis.

When there is indicators denoting the distance covered by a person, the verb 'to walk' functions as bounded. For example: They walked the short distance to the hotel, followed by porters (Stone, 336); A month later the girl walked three miles from Neorhori to thank him fell on her knees and kissed shoes (I.Stone, 139). Indicators denoting path and distance "short distance" "three miles" serve to represent walking path and the terminal point, the end of motion. Given indicators "short distance" "three miles" take the whole scope and walking three miles or short distance, before coming to terminal point some motion is observed. That's why, we may conclude these examples as Process + Terminative Aspectual situation (P+TAS).

\footnotetext{
${ }^{12}$ Demonte V., McnallyL.,Telicity, Change, and State. Oxford University Press, 2012. -P 29.
} 
English prepositions and adverbials function productively in the formation of aspectual situations with motion verbs. They serve to indicate direction, coming to the terminal point of the motion denoted by the person, coverage of distance and also the beginning of motion. When the prepositions down, along combined with a noun expressing location, they give to the verb 'to walk' a trajectory motion. For example: We walked along the railroad track (Hem, 191);

He linked his arm through hers as they walked down the narrow sidewalks of Hanukkahs main street (Stone, 173); (58) We walked down the corridor (Hem,144).

In both examples, person moves forward describing a path denoted by locative noun. As the motion in process and there is no (not indicated) terminal or end point in context, we can conclude these predicates into PAS.

English adverbial "on" associated with some verbs form phrasal verbs with the meaning of continuation. The same function can be observed with the unit walk + on. For example: I walked on down a back street that led to a crosscut to the hospital (Hem,51).

The motion conducted along a path indicates a continual process, and is conceived as wide scope with PAS+C. if another on is added additional effort to continue a process is realized.

He walked on and on- additional effort with continuation expressing PAS.

An adverb away added to a motion verb 'to walk' denotes to indicate the leaving the present position and beginning of motion in particular direction. For example: I'll see you in a little while "Miss Barkley said" Miss Ferguson walked away in the dark (Hem, 47).

It is clear of a given example that, there is no destination point, so the observer conceives the situation as the beginning and continuation. From the point of view of destination, it can be considered as wide scope, and Inchoative+Process Aspectual situation (In+PAS).

While considering aspectual functions of the verb 'to walk', there have been found out that, it may represent several kinds of aspectual situations. The bounded function of the verb 'to walk' can be used in following occurrences: a) when there is a definite direction of a person with terminal point (direction and terminal point can be expressed by prepositions, adverbs and locative nominatives), composing TAS (short scope), b) bounded function is also observed in predicates covering the whole distance (by a person). In this case, the beginning point and the end point of a motion are clearly described by locative nominatives. From the point of view of an observer, it may also represent TAS with short scope.

The verb 'to walk' functions unbounded in the following cases: a) the motion of a person in space (direction is not indicated) expressing PAS with wide scope, b) manner of motion without direction expressing PAS also with wide scope, c) directive motion of a person (usually with prepositions along, down) without terminal point, functioning as PAS with wide scope, d) when there is beginning and further motion of a person (with an adverb away), expressing Inc+PAS denoting wide scope, e) further motion of a person in space as a continual process (with an adverb on) representing $\mathrm{PAS}+\mathrm{C}$, wide scope.

English equivalent of the verb 'to walk' in Uzbek may be chosen 'yurmoq' expressing the meaning of motion with feet. Except this meaning, Uzbek verb 'yurmoq' has grammatical function of auxiliary verb, giving various motional and actionable meaning to the main verb of a predicate. The verb 'yurmoq' has following meanings expressing motion: move forward on feet; tez yurmoq (fast walk) - walk fast, sekin yurmoq (slowly walk) - walk slowly, oqsab yurmoq (limp walk) - go limping. Otyurmayturaverdi (horse walk not stay) - The horse didn't walk. Yurgan daryo, o'tirganbo'yra (proverb).Kampir yurganda, hechqanday ovoz chiqmasdi - the old lady didn't make any noise when walking. Men so'qmoqdan yursam ham bo'ladi - I may walk on pathway. 2. Move on a particular direction, to go from a place to another (for transport means); mashina chap tomonga yurdi (the car left to walk) - the car turned to left. Mana endi u otsiz yuribdi (now he horse without walk) - And now he is going without w horse. 3 . To move on a space; Hovuzchada o'ntacha baliq yuripti (in the pool ten about fish walk) - there are about ten fish in the pool. Dasturxon ustida chumoli yuripti (the table on an ant walking) - There is an ant on the table. 4. To travel, making a trip on foot; Shaharma-shahar yurmoq (town to town walk) - to travel from a town to another town. 5. Qatnamoq. Markazdan qishlog'imizga avtobus yuradi. 5. To move on a particular direction; Mashina chap tomonga yurdi (the car to the left walk) - The car turned to the left. 
These meanings comprise semantics concerning motion. The verb 'yurmoq' has several other meanings. As we are discussing only semantics concerning motion, the other meanings are not discussed. The verb 'yurmoq' has also the function of an auxiliary verb. As an auxiliary verb, '-b, -a yur' is used to denote additional durative and continual meaning to the main verb of a predicate. Aspectual semantics of '-b, - yur' depended on the bounded and unbounded semantics of a main verb. Auxiliary verbs in Uzbek (and also in most Turkish languages) give additional meaning to the main verb, accordingly aspectual meaning too (that is the use of some verbs in the function of auxiliary usage which is also peculiar to motion verbs such as -bor (go), -kel (come), -ket (go away). Focusing on the semantics of verb lexemes or verb behavior with the interrelation with auxiliary verbs we may reveal unnoticed sides of semantic and conceptual data of predicates some other aspectual meanings. These auxiliary verbs give additional directive feature to the verb "yurmoq". As for the verb "yurmoq" itself shows the manner of walking: u eshikka yurib bordi (he to the door walk go went) "bounded feature- TAS) - he walked to the door. U yurib ketdi (he walk go (went) away) (bounded feature- InchAS) - he walked away. As the situations (or may be events) clearly indicate that the time, location and movement are conceived by an observer to have an end beginning of a movement conducted by a person.

\section{Conclusion:-}

1. Differences in aspectual situations are related to contextual surrounding and also determination of bounded and unbounded features of verb lexemes in the English language. In Uzbek, auxiliary verbs play a significant role in the formation of aspectual situations.

2. Aspectual situations with motion verbs are closely associated with nominal group of words denoting time, location, space, path, direction and quantitative expressions. That is peculiar to the English language. In Uzbek, not only nominal group of words expressing time, location, space, path, direction, but also auxiliary verbs play a role in forming aspectual situations. Bounded and unbounded features of verbs somehow influence denoting aspectual situations in formation analytical forms of Uzbek verbs. For example, when bounded main verb is associated with unbounded featured auxiliary verb a rind of iteration happens: kelib yur (come walk) - come often: sen yiqilib yurasan (you fall walk) - you often fall. If the main verb is unbounded auxiliary verb "-b yur" expresses continual meaning (CAS). For example, ishonibyurmoq (believe walk) - believe (in the time being), o'qib yurmoq (study walk) - study somewhere (at the time being).

3. Aspectual situations within motion verbs fall into summary scanning because of the occurrences expressed by motion verbs are received as description by the observer.

4. The analysis of aspectual situation differs from of those aspectual events. Aspectual situation considers all the contextual tools that affect the meaning of a predicate that form aspectual meaning (beginning, durativity, culmination, iterativity, terminativity, perfectivity, imperfectivity etc.)

5. DAS, PAS, TAS, P+TAS etc are properties of motion verbs conceptualized differently in situations. Aspectual situations with motion verbs are closely connected with manner, path, direction, space and location in English. So, the sense of motion varies on aspectual view point across language on the basis of conceptualization. That's the reason of varying linguistic units expressing motion through aspectual situation.

6. In Uzbek, motion displays better with verb satellite, whereas in English motion displays better recall of manners of motion andof paths. These differences correlate with the conceptual representations receiving linguistic emphasis in each language. This correlation may correspond to attention to dynamic aspects of motion scenes interacting aspectual situation.

7. Aspectual situations of motion verbs display in memory through scanning the situation as a whole completed, durative, procession, terminative, inchoative and also two aspectual semantics correlated as procession+terminative, inchoative+procession and so on. From the cognitive view of point the same motion is not only expressed differently by the two languagecommunities, but that its details and sub-events are also memorized and inferred differentlyin cognition. 